\title{
DESIGN AND COMPARATIVE EVALUATION OF CLARITHROMYCIN GASTRIC BIOADHESIVE TABLETS BY EX VIVO AND IN VIVO METHODS
}

\author{
NISHAD KM ${ }^{1 *}$, ARUL B ${ }^{2}$, RAJASEKARAN S \\ ${ }^{1}$ Department of Pharmaceutics, Institute of Pharmaceutical Sciences and Research Centre, Bhagwant University, Ajmer, \\ Rajasthan - 305 004, India. ${ }^{2}$ Department of Pharmaceutics, Vinayaka Mission College of Pharmacy, Salem, Tamil Nadu, India. ${ }^{3}$ Department \\ of Pharmacology, Jamia Salafiya Pharmacy College, Pulikkal, Malappuram, Kerala, India. Email: nishadcvr@gmail.com
}

Received: 21 November 2017, Revised and Accepted: 11 January 2018

ABSTRACT

Objective: The present investigation was to formulate controlled release of mucoadhesive clarithromycin tablets using natural polymers.

Methods: Tamarind seed polysaccharide obtained from Tamarindus indica and chitosan act as natural polymers. The formulated tablets of the combined form of thrombospondin (TSP) and chitosan were analyzed by in vitro dissolution method. The optimized formulations were selected for ex vivo and in vivo studies and compared with hydroxypropyl methylcellulose K100 polymer by evaluating gastric retention period by X-ray imaging technique, and drug bioavailability by a pharmacokinetic method from blood samples was determined by high-performance liquid chromatographymass spectrometry method.

Results: The gastric mucoadhesive tablets were prepared using chito-TSP polymers. The in vitro drug release showed good release character for $24 \mathrm{~h}$. The ex vivo studies of tablets showed good adhesive property for a long time. The X-ray imaging technique also proved the adhesive character of tablets. From blood serum sample of rabbits, bioavailability of the drug is in according to the controlled release mechanism.

Conclusion: The selected formulations were subjected to stability studies. The study concluded that combination of chitosan and TSP is best natural polymer for mucoadhesion by the advantages of controlled release and biodegradation.

Keywords: Tamarind seed polysaccharide, Mucoadhesive tablets, Clarithromycin, X-ray, High-performance liquid chromatography-mass spectrometry, ex vivo methods.

(c) 2018 The Authors. Published by Innovare Academic Sciences Pvt Ltd. This is an open access article under the CC BY license (http://creativecommons. org/licenses/by/4. 0/) DOI: http://dx.doi.org/10.22159/ajpcr.2018.v11i4.24325

\section{INTRODUCTION}

Macrolide antibiotics considered the first line drugs for the treatment of bacterial infections. Helicobacter pylori is bacteria causing peptic ulcer. Clarithromycin tablets are very effective medication for this treatment [1]. The half-life (3-4 h) and dosing frequency once daily clarithromycin is an ideal drug for controlled release. The objective of the present study is to reduce the frequency of administration and to improve the patient compliance [2]. The present study aims to develop controlled released mucoadhesive tablets of clarithromycin using thrombospondin (TSP)-chitosan as natural polymer. The oral route is selected for the administration, because it is safe and biodegradable [3]. The aim of work was to formulate clarithromycin mucoadhesive tablets followed by in vitro, ex vivo, and in vivo studies.The tablet binding efficiency and pharmacokinetic property were confirmed with comparative studies with hydroxypropyl methylcellulose (HPMC) $\mathrm{K}-100$ by X-ray imaging technique and from blood serum analysis using high-performance liquid chromatography-tandem mass spectrometry (HPLC-MS) method. The stability studies were performed as per ICH guidelines for the optimized formulation.

\section{METHODS}

Chemicals and reagents

All chemicals, reagents and solvents used in the study were of analytical grade.

\section{Preformulation studies}

Preformulation studies of drug, polymer, and granules were performed including Fourier transform infrared (FTIR) compatibility studies $[4,5]$. The tablets were formulated according to dry granulation method. The compressed mucoadhesive tablets were evaluated for in vitro dissolution studies using USP XXII dissolution test apparatus for each formulation. Jar was filled with $\mathrm{HCl}$ buffer $\mathrm{pH} 1.2$ and temperature was maintained at $37 \pm 0.5^{\circ} \mathrm{C}$. Paddle was revolved at $100 \mathrm{rpm}$ speed. $5 \mathrm{ml}$ of sample was withdrawn after interval of $2 \mathrm{~h}$ and replaced with $5 \mathrm{ml}$ of fresh dissolution medium to maintain sink condition. Samples were then analyzed spectrophotometrically for drug content at $210 \mathrm{~nm}[6]$.

Bioadhesive studies (ex vivo methods)

The bioadhesive properties of chito-TSP polymers and tablets were determined using goat ileum. The different adhesive strength and adhesive force were evaluated.

\section{Determination of adhesive strength of polymer (ex vivo)} Wilhelmy method

Take a small slide of $(2 \times 5 \mathrm{~cm})$ length which is coated by $1 \% \mathrm{~W} / \mathrm{V}$ solution of mucoadhesive agent. The slides were dipped in the mucin solution in beaker by maintaining the temperature $30^{\circ} \mathrm{C}$ the one end of the slide is connected to nylon thread and the other end is to keep the weights. The slides were withdrawn in different time intervals of $5,10,15$, and $30 \mathrm{~min}$. The experiments were performed for selected formulation [7] (Fig. 1). Result datas were shown in Table 3.

\section{Study of mucoadhesive strength for tablets}

Measurement of adhesive strength by in vitro wash of test

The experiment was performed by disintegration test apparatus. The cylinder part of disintegration tester was removed which is replaced by glass slide $\left(10 \times 2 \mathrm{~cm}^{2}\right)$. The slide was attached with stainless steel plate. 
Table 1: In process evaluation of formulated tablets

\begin{tabular}{|c|c|c|c|c|c|c|c|}
\hline Formulations & Wt variation mg & Thickness (mm) & Length (mm) & Breadth (mm) & Hardness $\left(\mathrm{Kg} / \mathrm{cm}^{2}\right)$ & Friability (\%) & $\begin{array}{l}\% \text { drug content } \\
\% w / w\end{array}$ \\
\hline F1 & 760 & 5.65 & 10.95 & 9.46 & 6.5 & 0.74 & 93.46 \\
\hline F2 & 773 & 5.63 & 10.96 & 9.48 & 5.8 & 1.02 & 94.56 \\
\hline F3 & 784 & 5.65 & 10.96 & 9.46 & 6.2 & 0.85 & 95.62 \\
\hline $\mathrm{F} 4$ & 776 & 5.64 & 10.95 & 9.47 & 6.0 & 0.91 & 93.21 \\
\hline F5 & 778 & 5.66 & 10.96 & 9.48 & 5.9 & 0.80 & 92.15 \\
\hline F6 & 775 & 5.67 & 10.95 & 9.46 & 6.2 & 0.76 & 95.66 \\
\hline
\end{tabular}

All the tablet formulations showed acceptable pharmaco technical properties

Table 2: In vitro dissolution study of clarithromycin mucoadhesive tablets

\begin{tabular}{|c|c|c|c|c|c|c|c|}
\hline \multirow[t]{2}{*}{ Time in hour } & \multicolumn{7}{|c|}{ Cumulative \% drug release of different formulations } \\
\hline & F1 & F2 & F3 & F4 & F5 & F6 & F7 \\
\hline 1 & 7.79 & 7.02 & 6.29 & 5.65 & 4.37 & 5.05 & 7.05 \\
\hline 4 & 32.11 & 28.62 & 28.91 & 27.08 & 15.22 & 20.74 & 25.23 \\
\hline 8 & 59.48 & 48.91 & 55.05 & 44.82 & 34.20 & 37.11 & 38.78 \\
\hline 12 & 86.34 & 76.79 & 74.17 & 58.45 & 50.48 & 54.08 & 50.25 \\
\hline 14 & 97.79 & 87.71 & 88.45 & 70.28 & 58.51 & 63.59 & 65.24 \\
\hline 16 & - & 99.51 & 100.02 & 77.94 & 63.62 & 71.14 & 79.24 \\
\hline 18 & - & - & - & 86.74 & 72.77 & 79.79 & 84.24 \\
\hline 20 & - & - & - & 93.60 & 79.79 & 86.91 & 93.98 \\
\hline 22 & - & - & - & 98.48 & 85.37 & 93.85 & 102.61 \\
\hline 24 & - & - & - & - & 94.11 & 99.51 & - \\
\hline
\end{tabular}

Table 3: Mucoadhesive strength of different polymers

\begin{tabular}{lll}
\hline \multirow{2}{*}{ Time (min) } & \multicolumn{2}{l}{ Mucoadhesive strength $(\mathbf{g}) \mathbf{n = 3}$} \\
\cline { 2 - 3 } & HPMC K-100 & CHITO-TSP \\
\hline 05 & 0.85 & 0.96 \\
10 & 0.91 & 1.34 \\
15 & 1.21 & 1.62 \\
30 & 1.55 & 1.89 \\
60 & 1.90 & 2.10 \\
\hline
\end{tabular}

HPMC K: Hydroxypropyl methylcellulose, TSP: Thrombospondin

Table 4: Mucoadhesive strength by detachment force method

\begin{tabular}{lllll}
\hline Time & $\mathbf{5}$ $\mathbf{~ i n}$ & $\mathbf{1 0} \mathbf{~}$ in & $\mathbf{1 5} \mathbf{~}$ in & $\mathbf{3 0} \mathbf{~ m i n}$ \\
\hline Adhesion strength $(\mathrm{g})$ & 26.55 & 50.15 & 73.28 & 95.24 \\
Adhesive force $(\mathrm{N})$ & 0.255 & 0.4905 & 0.7161 & 0.9343 \\
\hline
\end{tabular}

Adhesive force $=$ (adhesive strength $/ 1000) \times 9.81$

Table 5: Peak area clarithromycin samples

\begin{tabular}{ll}
\hline $\begin{array}{l}\text { Known concentration of standard drug } \\
\text { clarithromycin }\end{array}$ & Peak area \\
\hline 5 & 9322 \\
10 & 14446 \\
20 & 24826 \\
40 & 42536 \\
80 & 69128 \\
160 & 112442 \\
320 & 244368 \\
640 & 485265 \\
\hline
\end{tabular}

The intestine part of $3 \times 2 \mathrm{~cm}^{2}$ was fitted on the slide and tied with thread. The tablet was pressed with pressure and dipped the slide in $500 \mathrm{ml}$ of $0.1 \mathrm{~N}$ solution and operated the machine (Fig. 2). The time to detach the tablet from tissue surface was considered as wash of time for the tablet [8].

\section{In vivo bioadhesive study}

Determination of gastric retention time by X-rayimaging technique Healthy adult Male New Zealand white strain rabbits weighing 1.5-

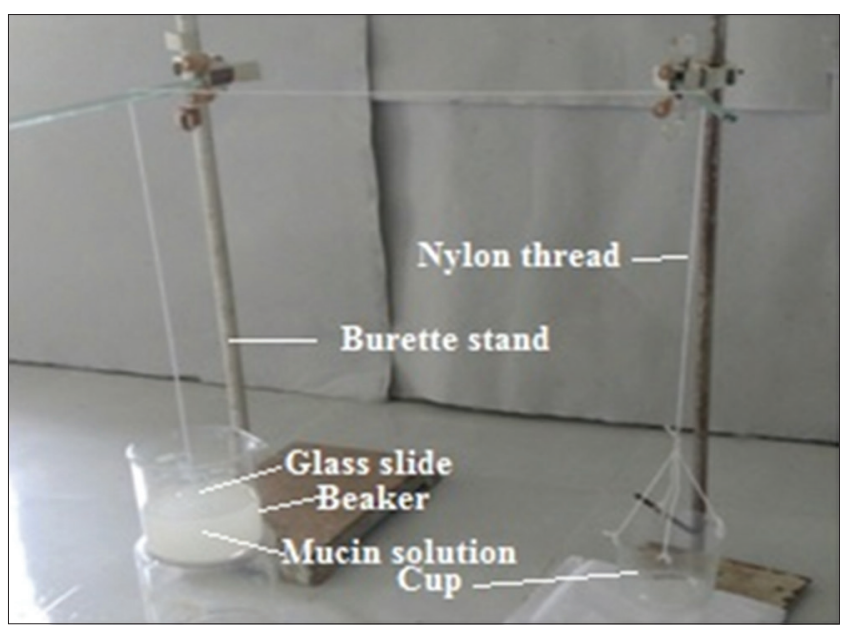

Fig. 1: Wilhelmy method to measure mucoadhesive strength

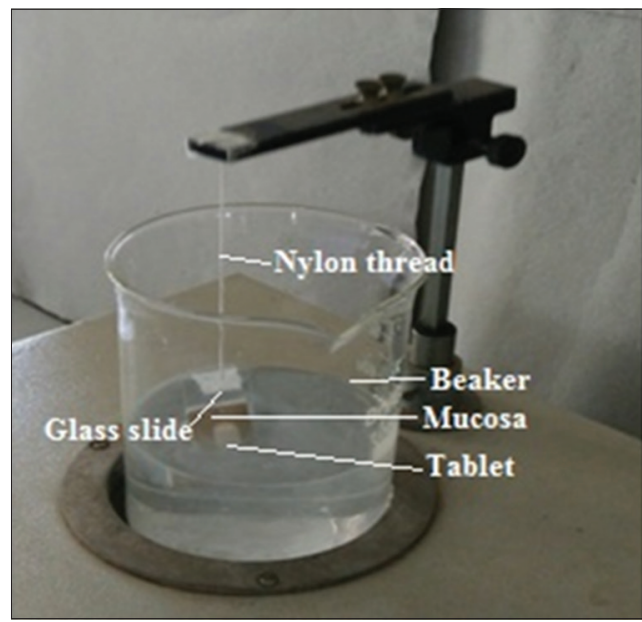

Fig. 2: In vitro wash of test method 
Table 6: In vivo bioavailability study of Clarithromycin+HPMC K-100 polymer in rabbit

\begin{tabular}{|c|c|c|c|c|c|c|c|}
\hline \multicolumn{4}{|c|}{ Trapezoid Calculation of AUC (ng-hr/ml) } & \multicolumn{4}{|c|}{ Trapezoid Calculation of AUMC (ng-hr*hr/ml) } \\
\hline Time (h) & Conc. (ng/ml) & Partial & Cumulative & Time (h) & Time $x$ Conc. & Partial & Cumulative \\
\hline 0.0 & 0.0 & 0.00 & 0.00 & 0.0 & 0.0 & 0.00 & 0.00 \\
\hline 0.5 & 122.6 & 30.66 & 30.66 & 0.5 & 61.3 & 15.33 & 15.33 \\
\hline 2.0 & 208.2 & 248.13 & 278.79 & 2.0 & 416.4 & 358.29 & 373.62 \\
\hline 4.0 & 370.1 & 578.26 & 857.05 & 4.0 & 1480.2 & 1896.64 & 2270.26 \\
\hline 8.0 & 303.2 & 1346.52 & 2203.57 & 8.0 & 2425.6 & 7811.68 & 10081.94 \\
\hline 12.0 & 249.1 & 1104.60 & 3308.17 & 12.0 & 2989.2 & 10829.60 & 20911.54 \\
\hline 24.0 & 102.7 & 2110.80 & 5418.97 & 24.0 & 2464.8 & 32724.00 & 53635.54 \\
\hline
\end{tabular}

AUC: Area under the curve

Table 7: In vivo bioavailability study of Clarithromycin+Cheto-TSP polymer in rabbit

\begin{tabular}{|c|c|c|c|c|c|c|c|}
\hline \multicolumn{4}{|c|}{ Trapezoid Calculation of AUC (ng-hr/ml) } & \multicolumn{4}{|c|}{ Trapezoid Calculation of AUMC (ng-hr*hr/ml) } \\
\hline Time (h) & Conc. (ng/ml) & Partial & Cumulative & Time (h) & Time $x$ Conc. & Partial & Cumulative \\
\hline 0.0 & 0.0 & 0.00 & 0.00 & 0.0 & 0.0 & 0.00 & 0.00 \\
\hline 2.0 & 237.9 & 278.78 & 312.23 & 2.0 & 475.8 & 407.03 & 423.75 \\
\hline 4.0 & 390.9 & 628.80 & 941.03 & 4.0 & 1563.6 & 2039.40 & 2463.15 \\
\hline 8.0 & 313.7 & 1409.20 & 2350.23 & 8.0 & 2509.6 & 8146.40 & 10609.55 \\
\hline 12.0 & 304.9 & 1237.20 & 3587.43 & 12.0 & 3658.8 & 12336.80 & 22946.35 \\
\hline 24.0 & 108.1 & 2477.70 & 6065.13 & 24.0 & 2593.2 & 37512.00 & 60458.35 \\
\hline
\end{tabular}

AUC: Area under the curve, AUMC: Area under momentum curve

Table 8: Concentration comparison of in vivo release of clarithromycin+HPMC-K100 polymer and clarithromycin+Chito-TSP polymer

\begin{tabular}{lll}
\hline Time in (h) & Concentration in $\mathbf{~} \mathbf{c g} / \mathbf{m l}$ & \\
\cline { 2 - 3 } & Clarithromycin+HPMK100Polymer & Clarithromycin+Chito-TSP polymer \\
\hline 0.0 & 0.0 & 0.0 \\
0.5 & 122.6 & 133.8 \\
2.0 & 208.2 & 237.9 \\
4.0 & 370.1 & 390.9 \\
8.0 & 303.2 & 313.7 \\
12.0 & 249.1 & 304.9 \\
24.0 & 102.7 & 108.1 \\
\hline
\end{tabular}

AUC: Area under the curve, AUMC: Area under momentum curve, HPMC K: Hydroxypropyl methylcellulose

Table 9: Pharmacokinetic parameters from serum analysis

\begin{tabular}{lll}
\hline Formulation & AUC (0-t) & C max \\
\hline Clarithromycin+HPMC K-100 Polymer & $5419 \mathrm{ng}-\mathrm{h} / \mathrm{ml}$ & $370.1 \mathrm{ng} / \mathrm{ml}$ \\
Clarithromycin+Chito-TSP polymer & $6065 \mathrm{ng}-\mathrm{h} / \mathrm{ml}$ & $4 \mathrm{~h}$ \\
\hline
\end{tabular}

AUC: Area under the curve, HPMC K: Hydroxypropyl methylcellulose

$2.5 \mathrm{~kg}$ were used for the study. The animals were housed in cages and were kept in well ventilated with $100 \%$ fresh air by air handling unit. A 12 light/dark cycle were maintained. Room temperature was maintained between $22 \pm 2^{\circ} \mathrm{C}$ and relative humidity $50-65 \%$. They were provided with food and water ad libitum [9]. All the animals were acclimatized to the laboratory for 14 days before the start of the study. The experimental protocol was approved by the Institutional Animal Ethics Committee [10].

\section{Drug administration}

Animals were divided in to two groups. Group I administered with clarithromycin tablet coated with chitosan-TSP polymer and Group II rabbits were treated with clarithromycin tablet coated with HPMC K- 100 polymer. All animals were fastened for overnight with free access to water and before drug administration rabbits were feed orally with $2 \mathrm{ml}$ of saline for evaluating the floating nature of the tablet within the stomach (Figs. 3 and 4). Dose of drug is $40 \mathrm{mg} / \mathrm{Kg}$ [11].

Radio graphical examination - X-ray

After administration of standard and trial drug by intramuscular route, rabbits were anesthetized with ketamine and xylazine anesthetic agents and were exposed to X-ray to ascertain the location and nature of tablet in the stomach [9].

\section{Pharmacokinetic studies of in vitro dissolution}

Kinetics of drug release

The order of rug release can be assessed by graphical treatment of drug release data. A plot of \% drug remaining versus time would be linear if the drug release follows zero order (i.e., concentration-independent release). A plot of log of \% remaining drug versus time would be linear, if the drug release follows first order (i.e., concentration-dependent release) [12].

\section{Determination of pharmacokinetic data (in vivo method)}

Blood sample collection

After drug administration the blood samples were collected from the marginal ear vein of the rabbits for HPLC-MS analysis during $30 \mathrm{~min}$, 2 h, 4 h, 8 h, 12 h, and 24 h (Figs. 5 and 6).

Extraction

Blood samples collected from the rabbit were subjected to centrifugation to isolate serum and then about $0.4 \mathrm{ml}$ of rabbit serum was subjected 
to liquid: Liquid extraction. $200 \mu \mathrm{l}$ of serum sample werSe mixed with $1000 \mu \mathrm{l}$ of water, and $1000 \mu \mathrm{l}$ of sodium carbonate and methyl-t-butyl ether $(2000 \mu \mathrm{l})$ were added to the sample (Fig. 7).

The samples were vortexed and centrifuged. The ether layer was transferred to a clean tube and evaporated under nitrogen to dryness. The residue was reconstituted in $100 \mu \mathrm{l}$ of $23 \%$ acetonitrile- $77 \%$ $(50.0 \mathrm{~mm})$ ammonium acetate $(\mathrm{pH} 4.90 \pm 0.05)$. The collected samples were shown in Fig. 7.

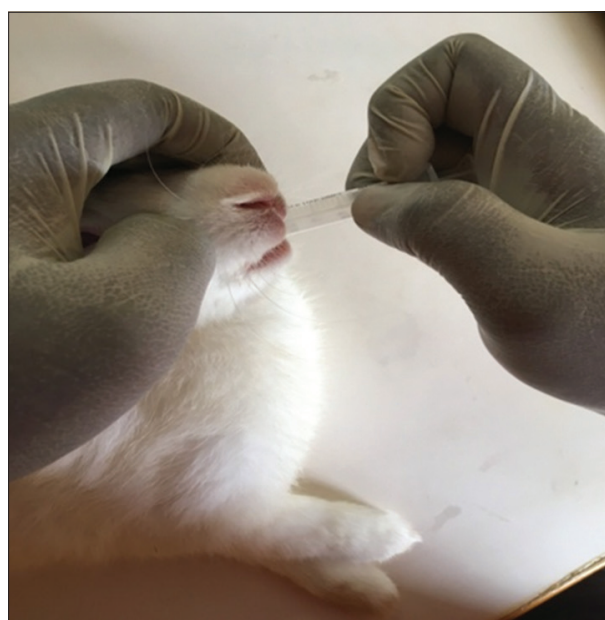

Fig. 3: Oral drug administration of Drug I

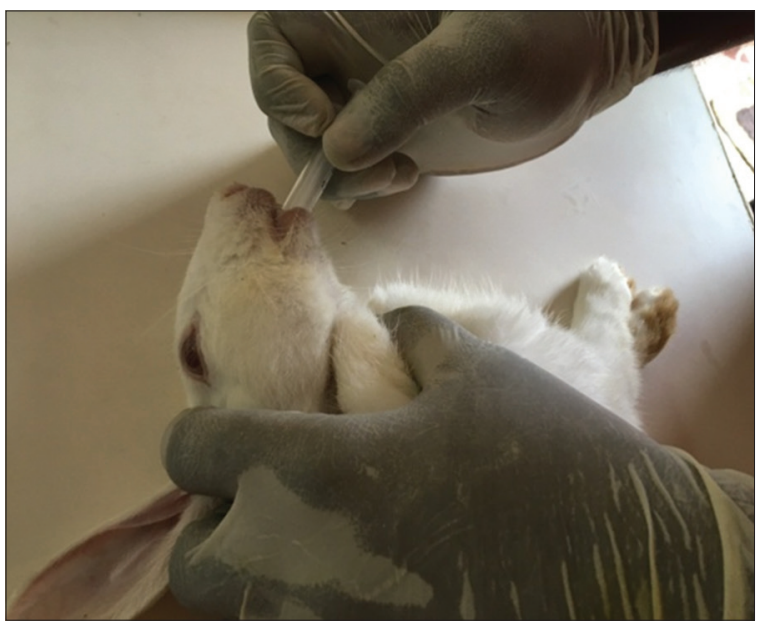

Fig. 4: Oral drug administration of Drug II

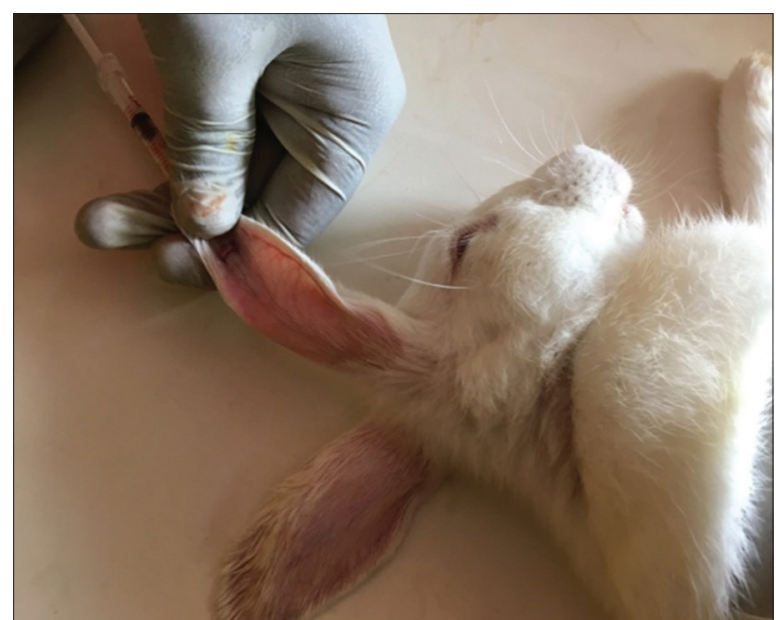

Fig. 5: Sample collection - Group I

\section{HPLC QT Specification}

- $\quad$ C18 column $0.3 \mathrm{ml} / \mathrm{min}, 10 \mathrm{ul}$ injection volume.

- Mobile Phase: 0.1\% Formic acid 40\% and acetonitrile 60\%.

- $\quad$ Shimadzu LCMS- 803.

The data obtained for group II and group I animals were shown Figs. 6 and 7 the graphical representation of cumulative AUC and AUMC were plotted as well as HPLC-MS chromatogram for different time intervals. For group II (Figs. 8-10) and group I (Figs. 11-13) respectively.

\section{Stability studies}

The purpose of stability testing is to provide evidence on how the quality of a drug substance or drug product varies with time under the influence of a variety of environmental factors such as temperature, humidity, and light and to establiSsh a retesting for the drug substance or a shelf-life for the drug product and recommended storage conditions [11].

Hence, formulation No.F6 was subjected to determine its shelf life, i.e., stability study using accelerated stability chamber. The tablets were packed and stored in the stability chamber under desired temperature and humidity given below for 6 months.

\section{RESULTS AND DISCUSSIONS}

\section{Preformulation studies of tablets}

The results of micrometric properties were performed. The results indicate that clarithromycin raw material shown passable flow property with the angle of repose of $32.92^{\circ}$ and the granule ready for compression was found to be $28.76^{\circ}$, it shows good flow property. The bulk density, tapped density, compressibility index, and Hausner ratio

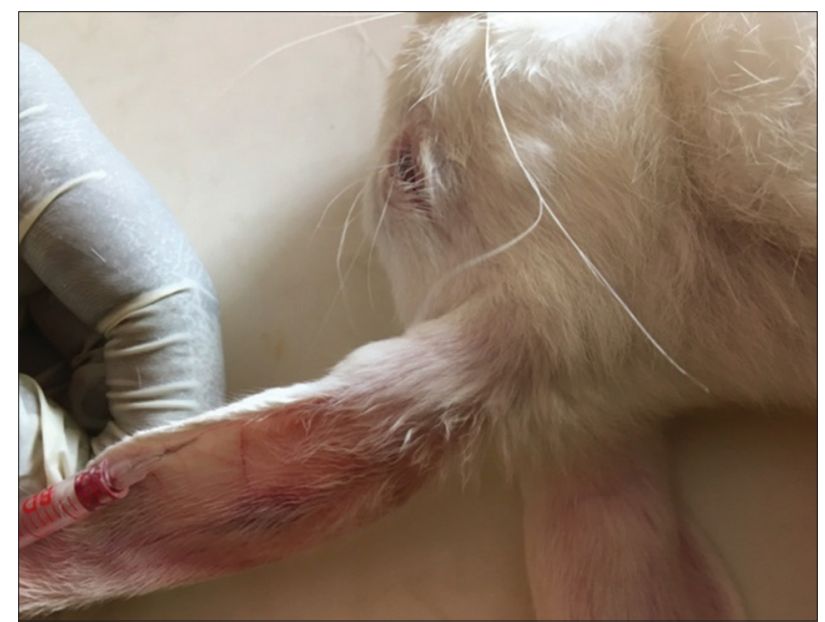

Fig. 6: Sample collection - Group II

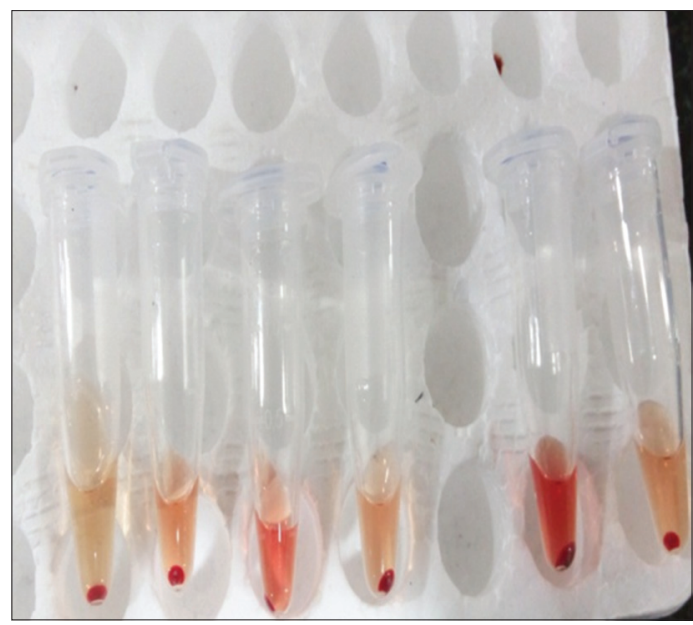

Fig. 7: Isolated serum 


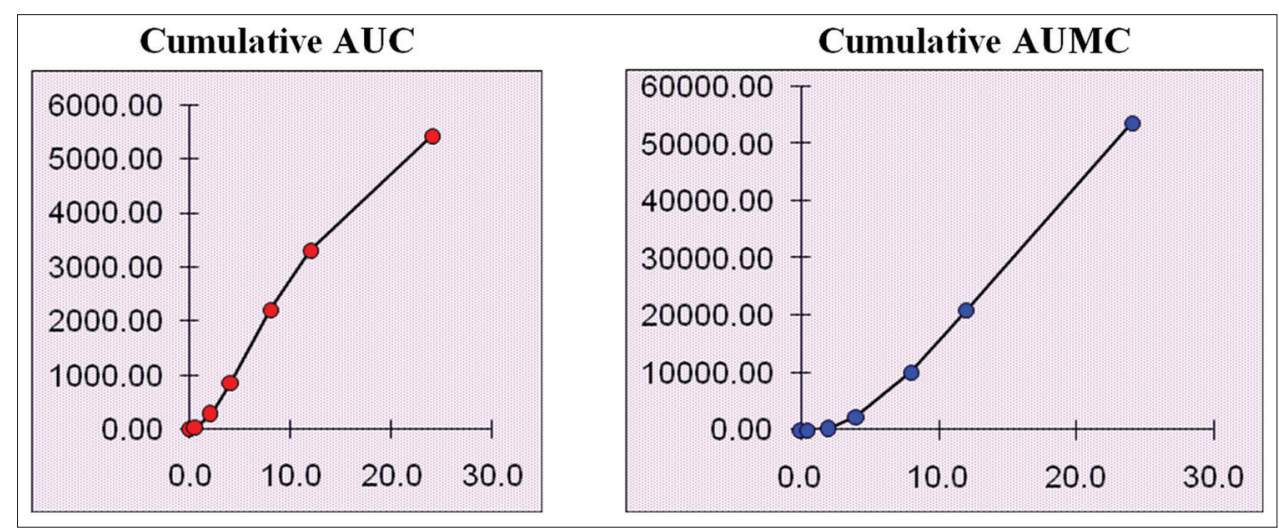

Fig. 8: Cumulative area under the curve and area under momentum curve of the drug sample

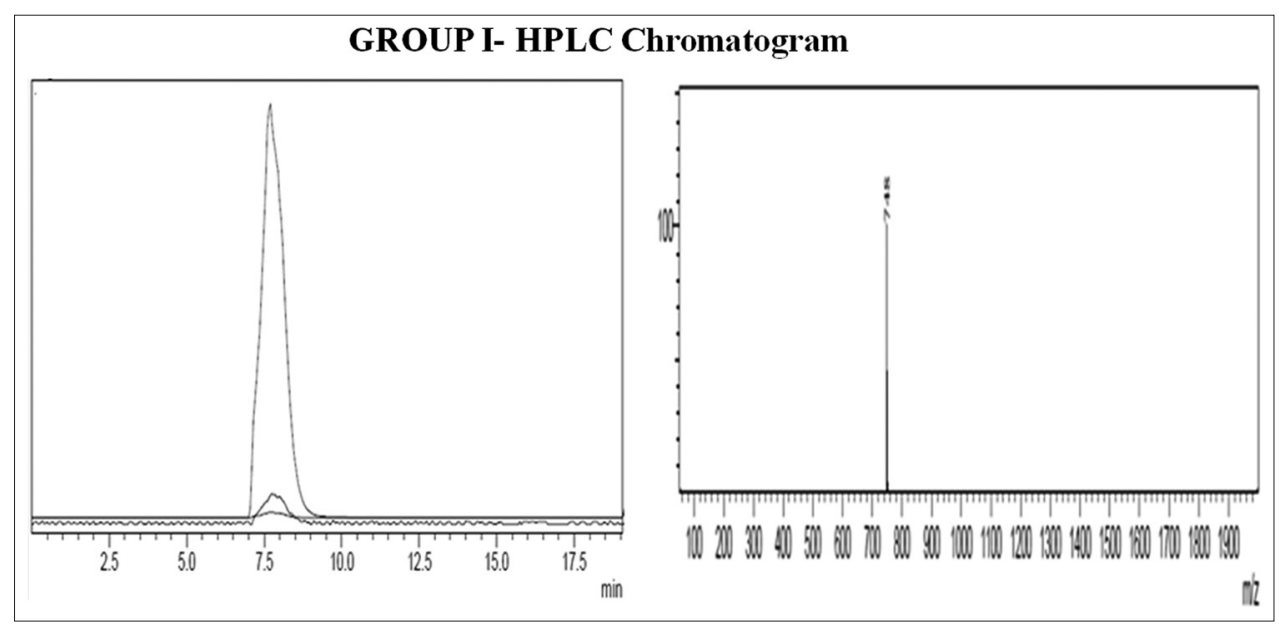

Fig. 9: High-performance liquid chromatography-tandem mass spectrometry Chromatogram 30 min

\begin{tabular}{llll}
\hline Time in h & Retention time & Area (\%) & Mol.wt \\
\hline $30 \min$ & 7.8 & 98412 & 748 \\
\hline
\end{tabular}

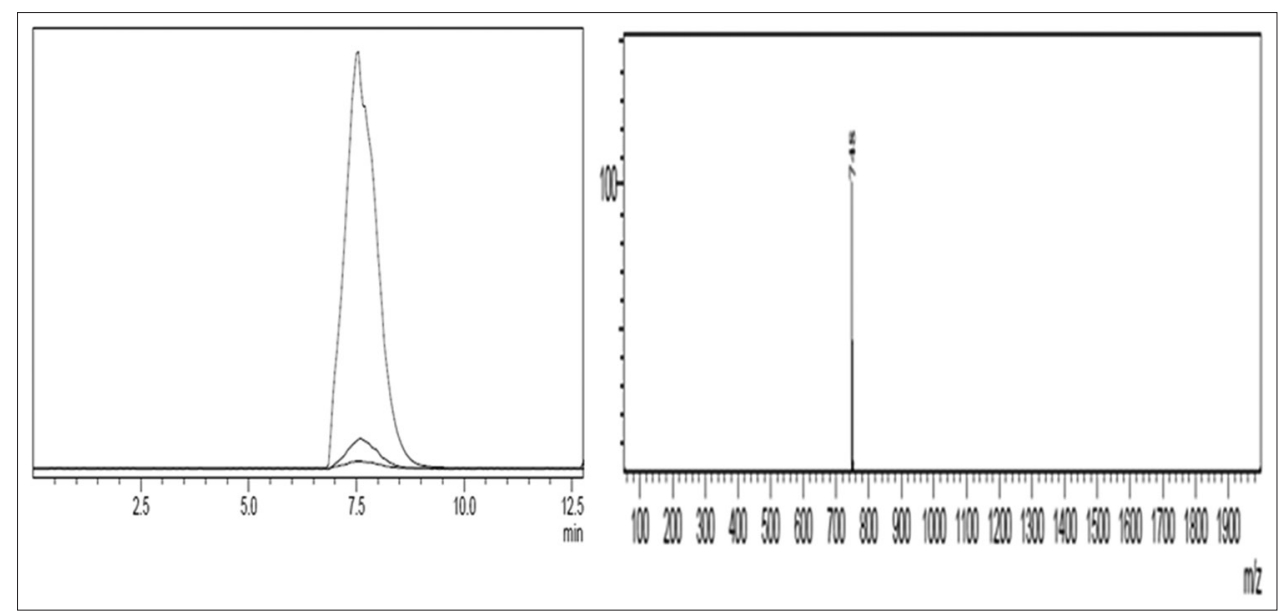

Fig. 10: High-performance liquid chromatography-tandem mass spectrometry Chromatogram $24 \mathrm{~h}$

\begin{tabular}{llll}
\hline Time in $\mathbf{h}$ & Retention time & Area (\%) & Mol.wt \\
\hline $30 \mathrm{~min}$ & 7.70 & 106755 & 748 \\
\hline
\end{tabular}




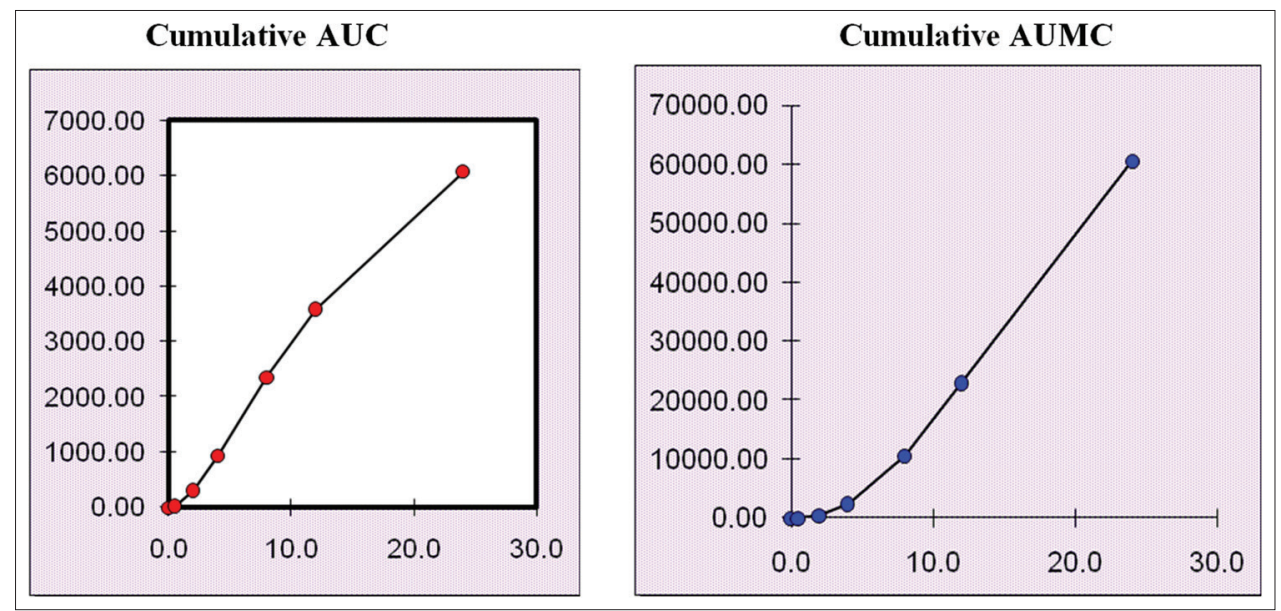

Fig. 11: Cumulative area under the curve and area under momentum curve of drug sample

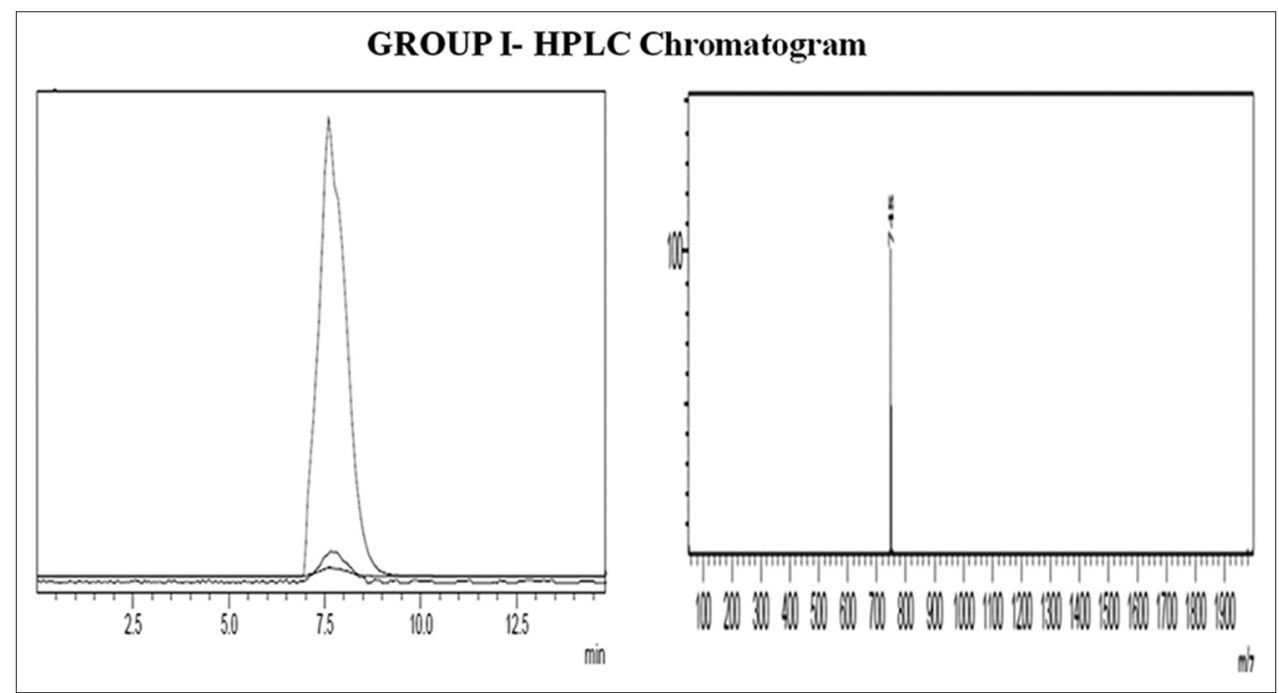

Fig. 12: High-performance liquid chromatography-tandem mass spectrometry chromatogram 30 min

\begin{tabular}{llll}
\hline Time in h & Retention time & Area (\%) & Mol.wt \\
\hline 30 min & 7.70 & 106755 & 748 \\
\hline
\end{tabular}
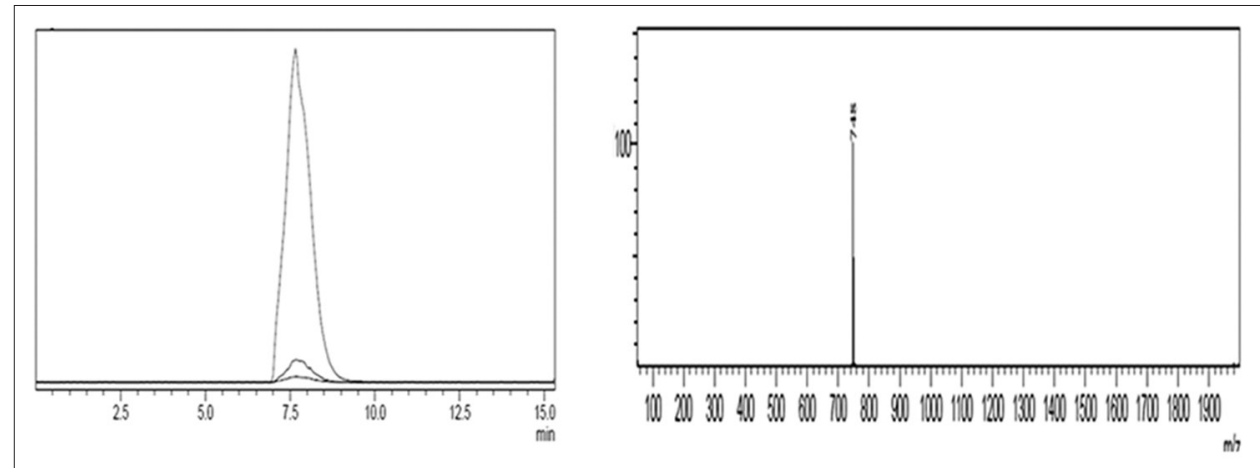

Fig. 13: High-performance liquid chromatography-tandem mass spectrometry Chromatogram $24 \mathrm{~h}$

\begin{tabular}{llll}
\hline Time in h & Retention time & Area (\%) & Mol.wt \\
\hline $24 \mathrm{~h}$ & 7.65 & 87521 & 748 \\
\hline
\end{tabular}


were observed. It revealed that the formulated granules showed good flow characters and good compression capacity.

\section{Drug excipient compatibility studies}

\section{FTIR analysis of clarithromycin}

An FTIR spectrum of clarithromycin was obtained in the range of $400-4000 \mathrm{~cm}^{-1}$ using $\mathrm{KBr}$ pellet technique and the peaks mentioned in standards were compared with those obtained (Figs. 14-16).

Furthermore, FTIR study of polymers, a combination of polymers and whole granular powder also performed for incompatibility test. The spectrum was obtained in the range of $4004000 \mathrm{~cm}^{-1}$ using $\mathrm{KBr}$ pellet technique and the peaks mentioned in standards were compared with those obtained. There was no evidence of any interaction between drugs and polymers.

Formulation and evaluation of clarithromycin mucoadhesive tablet

In-process evaluation studies were performed for prepared tablets, the obtained datas were mentioned (Table 1).

In vitro dissolution study clarithromycin mucoadhesive tablet The in vitro dissolution study of all formulations were performed using type II paddle type apparatus. The different drug release were mentioned with respect to time (Table 2). The graphical representation of cumulative drug release against time were shown Fig. 17.

Determination of adhesive strength of polymers Wilhelmy method The comparative mucoadhesive strength for HPMC K-100 and chitoTSP polymer were performed up to $60 \mathrm{~min}$. It shows that when time is continuing the adhesive strength of polymer increases (Fig. 18). The chitoTSP polymer shows more adhesive strength than HPMC K-100 polymers.

\section{Determination of adhesive strength for tablets}

\section{A. Detachment force method}

Selected formulation (F6) were subjected to detatchment force method (Table 4) in different time intervals. Detachment force method

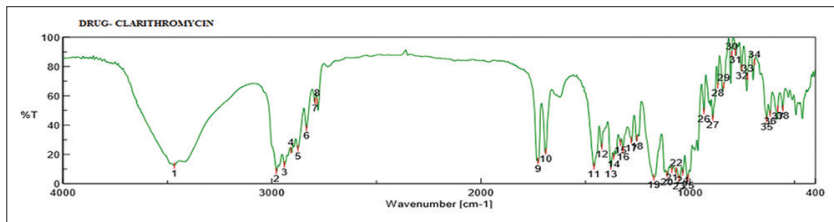

Fig. 14: Fourier transform infrared spectrum of clarithromycin raw drug

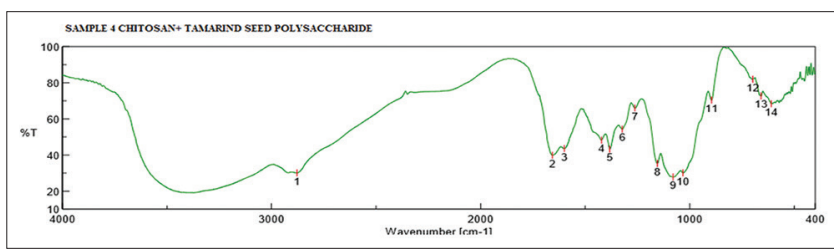

Fig. 15: Fourier transform infrared spectrum of a mixture of chitosan and thrombospondin

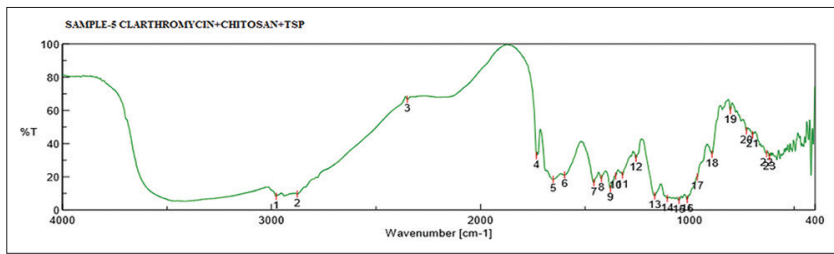

Fig. 16: Fourier transform infrared spectrum of mixture of clarithromycin, chitosan, and thrombospondin performed for to determine the adhesive strength and adhesive force. The test was carried out for different time intervals 5, 10, 15, and $30 \mathrm{~min}$, respectively. The weight required to detach the tablet from gastric mucosa is different at different time intervals. Hence, smore time contact increases the adhesion strength and adhesion force.

\section{Radio graphical examination - X-ray}

After administration of standard and trial drug by intramuscular route, rabbits were anesthetized with ketamine and xylazine anesthetic agents (2:1) and were exposed to X-ray imaging method of detection to ascertain the location and nature of tablet in the stomach. The $\mathrm{X}$-ray image of group I animals at different time intervals were shown Figs. 19-21.

The X-ray image of group I animals at different time intervals were shown Figs. 22-24.

The gastric retention time of mucoadhesive tablet was examined using $\mathrm{X}$-ray machine in rabbits. The tablets were administered by orally in the form of barium meal. The location of tablet in the rabbit stomach was identified in different time intervals of initial, $4^{\text {th }}$ and $8^{\text {th }} \mathrm{h}$, respectively. The experiment was carried out as comparative studies. Group-I rabbits were administered by chito-TSP polymers and GroupII rabbits were with HPMC K-100 polymers at the time of $8^{\text {th }} \mathrm{h}$ tablets were retain in Group-I rabbits. However, in Group-II rabbits, the tablets were found to be mild disintegration or disappearance. Hence,

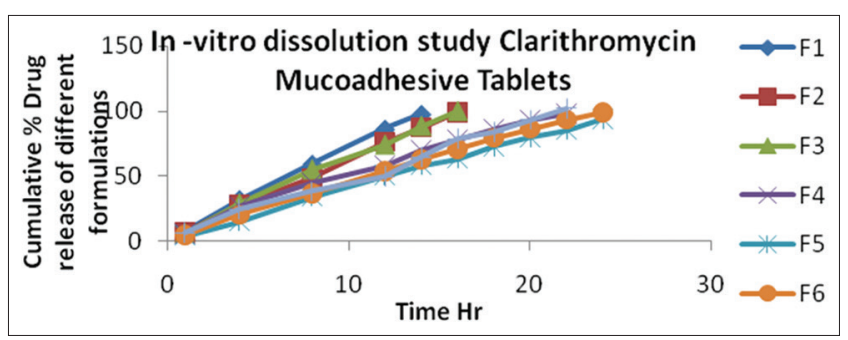

Fig. 17: In vitro drug release of mucoadhesive tablets

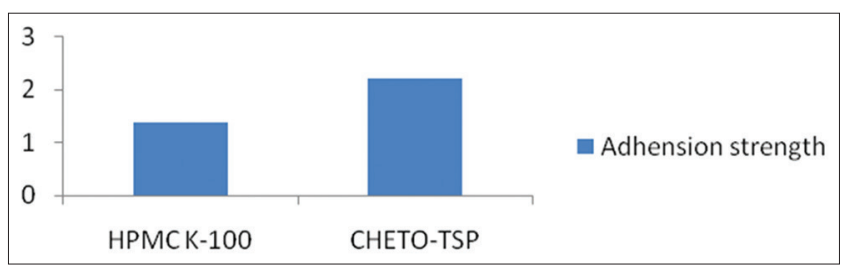

Fig. 18: Mucoadhesion strength at $60^{\text {th }}$ min

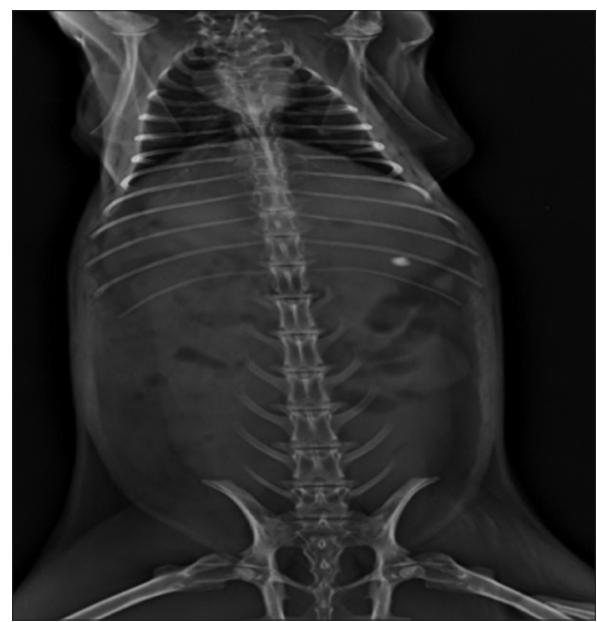

Fig. 19: Clarithromycin+Chito- thrombospondin polymer at $0^{\text {th }} h$ 


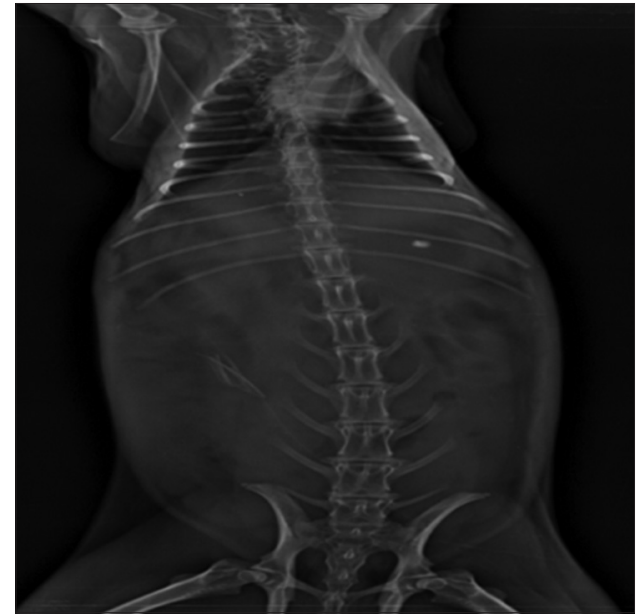

Fig. 20: Clarithromycin+Chito- thrombospondin polymer at $4^{\text {th }} \mathrm{h}$

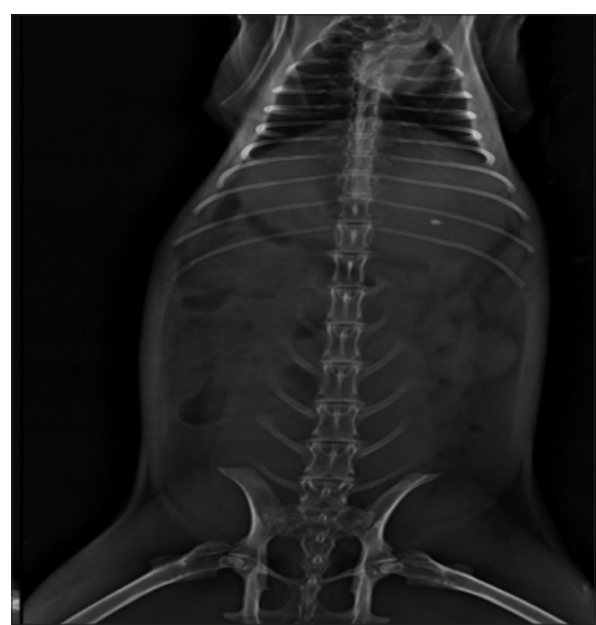

Fig. 21: Clarithromycin+Chito- thrombospondin polymer at $8^{\text {th }} h$

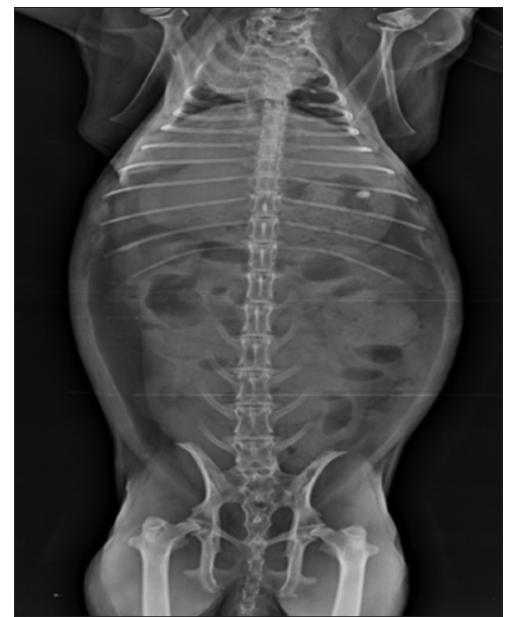

Fig. 22: Clarithromycin+hydroxypropyl methylcellulose K-100 at $\mathbf{0}^{\text {th }} \mathbf{h}$

a tablet with chito-TSP polymer shows good bioadhesive character for a long time.

Pharmacokinetics of in vitro release study

In vitro drug release follows zero-order kinetics for all the formulations. This may be due to release of clarithromycin from the

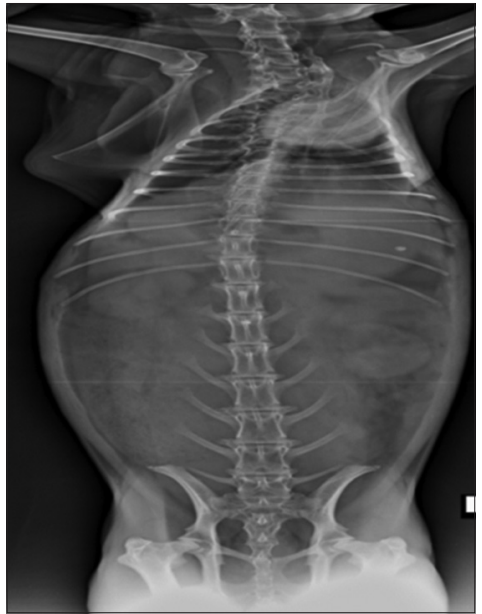

Fig. 23: Clarithromycin+hydroxypropyl methylcellulose K-100 at $4^{\text {th }} h$

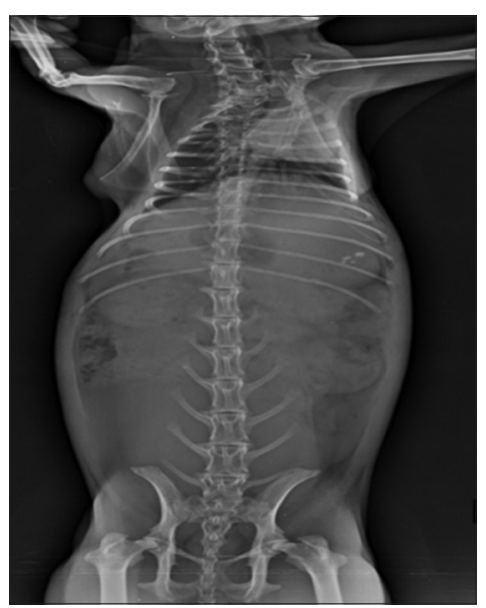

Fig. 24: Clarithromycin+hydroxypropyl methylcellulose K-100 polymer at $8^{\text {th }} \mathbf{h}$

surface of the swollen tablet. The kinetic treatment reflected that release data of selected formula F6 showed $\mathrm{r}^{2}=0.996$ which is close to 1 , indicating that release of drug follows zero-order kinetics. The in vitro drug release of F6 was best explained by Higuchi's equation, as the plots showed the highest linearity $\left(r^{2}=0.946\right)$. The drug release significantly follows a zero-order kinetic model for formulation F6. As the plot showed the highest linearity $\left(r^{2}=0.9891\right)$, the polymeric membrane was found through diffusion and rate of diffusion is controlled by these polymer.

Determination of pharmacokinetics data by serum analysis (in vivo study by HPLC-MS method)

The peak area obtained from serum analysis by HPLC-MS for known concentration of standared drug were shown Table 5.

Comparison of in vivo release of clarithromycin+HPMC-K100 polymer and clarithromycin+cheto-TSP polymer

The studies were performed and combined datas were mentioned (Table 8) for different time intervals.

The pharmacokinetic parameters of drug with polymers were noted and shown Table 9 and graphically represented (Fig. 25).

The pharmacokinetic study of serum analysis was performed by HPLC-MS technique. In which, the concentration of drug in each time interval and amount of drug also be determined quantitatively. The pharmacokinetic parameters such as AUC, $\mathrm{C}_{\text {max }}$ and $\mathrm{T}_{\max }$ were mentioned in the above table. Furthermore, the studies were conducted by a comparative method in two different rabbits. One rabbit administered 


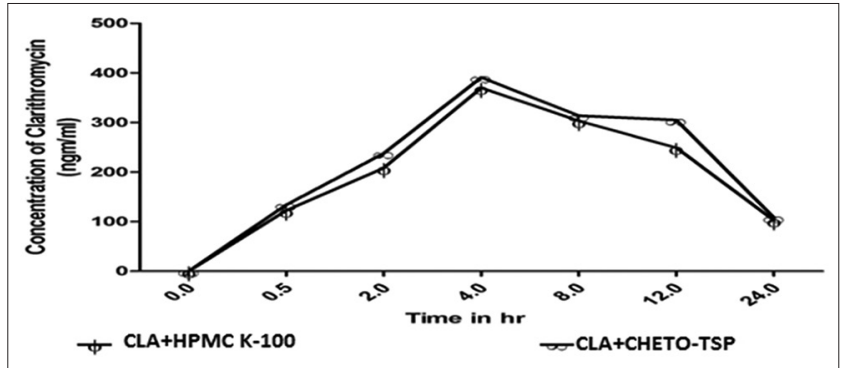

Fig. 25: Pharmacokinetics of drug clarithromycin in blood serum samples

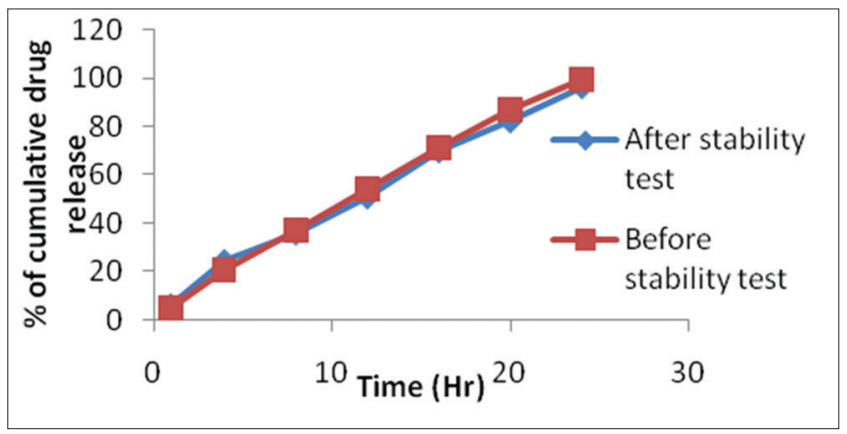

Fig. 26: In vitro release profiles of F6 before and after stability test

by clarithromycin tablet with HPMC K-100 polymer and another with chito-TSP polymer. The data showed that AUC, $\mathrm{C}_{\text {max }^{\prime}}$ and $\mathrm{T}_{\max }$ posses highest value in chito-TSP loaded tablet than HPMC K-100 loaded tablet. Hence, it is clear that formulation with chito-TSP polymer gives good bioavailability.

\section{Stability studies}

The stability studies were performed for selected formulation (F6) of clarithromycin mucoadhesive tablet as per the guidelines (Fig. 26). All the results evaluation studies were resembles with initial tablets. Hence, stability studies confirmed that the selected formulation (F6) has very good stable condition.

\section{CONCLUSION}

The study was under with the aim to development of controlled release mucoadhesive tablets of clarithromycin using natural polysaccharide. Here, the natural polysaccharides are tamarind seed polysaccharide and chitosan, which are drug release retarding agents for once daily dosage form. From Radio graphical Examination and pharmacokinetics tablets were found to be mild disintegration or disappearance. Hence, a tablet with chito-TSP compared to HPMC K100 polymer shows good bioadhesive character for a long time and pharmacokinetic properties.

\section{AUTHORS CONTRIBUTION}

Here by declare that, work was done by the authors mentioned in this article had made a very good efforts. Nishad KM collected the seeds of Tamarindus indica, Clarithromycin drug, analyzed the datas, performed all the laboratory procedures, wrote all the descriptive part. Dr Rajasekaran S assist for the in-vivo studies. Dr. B Arul guided and monitored the study.

\section{CONFLICT OF INTEREST}

The authors declare that, there is no conflict of interest related to the publication of this article.

\section{REFERENCES}

1. Khan MS, Rohitash K, Vijaykumar M, Pandey SC, Vishakante GD, Ahmed FM, et al. Development and evaluation of nasal mucoadhesive nanoparticles of an analgesic drug. Sch Res Libr Pharm Lett 2012;4:1846-54.

2. Kumar A, Singh N. Formulation and in vitro evaluation of combined floating mucoadhesive tablet of clarithromycin by using natural polymers. Int J Res Pharm Biomed Sci 2014;5:214-6.

3. Tejaswi BS, Sivadasan D, Devi S. Formulation and in vitro evaluation of clarithromycin floating microspheres for eradication of helicobacter pylori. Sch Res Libr Pharm Lett 2011;3:90-101.

4. Pawar Y, lalwani DN, Derle DV. Formulation and development of gastroretentive optimized once a day floating and/or bioadhesive tablet of ofloxacin. Int J Drug Deliv 2012;4:326-35.

5. Khurana S, Satheesh madhav NV. Mucoadhesive drug delivery: Mechanism and methods of evaluation. Int $J$ Pharm Biosci 2013;2:215-21.

6. Wadher KJ, Kakde RB, Umekar MJ. Formulation and evaluation of a sustained-release tablets of metformin hydrochloride using hydrophilic synthetic and hydrophobic natural polymers. Indian J Pharm Sci 2011;73:208-15

7. Singh S, Govind $\mathrm{M}$, Bothara $\mathrm{SB}$. A review on in vitro-in vivo mucoadhesive strength assessment. Pharma Tech Med 2013;1:221-7.

8. Bhanja S, Shafeeque MZ, Sudhakar M. Mucoadhesive buccal tablets of glimeperide- formulation and evaluation. Int J Pharm Pharm Sci 2013;5:111-4

9. Sudarshan S, Sunil B. In vivo mucoadhesive strength appraisal of gum manilkara zapota. Braz J Pharm Sci 2015;51:689-98.

10. Mukherjeea A, Sahoob NS, Sarmac HD. Preparation and evaluation of three mucoadhesive dosage forms using 99mTC-Ofloxacin. Appl Radiat Isot 2014;89:192-8.

11. Oliveira PR, Mendes C, Klein I, Sangoi MS, Bernardi LS, Silva MA. Formulation development and stability studies of norfloxacin extendedrelease matrix tablets. Biomed Res Int 2013;2013:716-36.

12. Goswami DS, Sharma M. Development of new mucoadhesive polymer from natural source. Asian J Pharm Clin Res 2012;5:212-5. 